\title{
Expression and prognostic value of circulating angiogenic cytokines in pancreatic cancer
}

\author{
Nuh N Rahbari ${ }^{1 *}$, Thomas Schmidt ${ }^{1}$, Christine S Falk², Ulf Hinz ${ }^{1}$, Magdalene Herber ${ }^{1}$, Ulrich Bork', \\ Markus W Büchler ${ }^{1}$, Jürgen Weitz ${ }^{1}$ and Moritz Koch ${ }^{1}$
}

\begin{abstract}
Background: The utility of circulating angiogenic cytokines (CAC) as biomarkers in pancreatic cancer has not been clarified yet. We investigated the expression and prognostic associations of seven CAC in patients with pancreatic cancer.

Methods: Serum samples were collected preoperatively in patients undergoing surgery for localized pancreatic cancer $(n=74)$, metastatic pancreatic cancer $(n=24)$ or chronic pancreatitis $(n=20)$ and in healthy controls $(n=48)$. Quantitative enzyme-linked immunosorbent assays and multiplex protein arrays were used to determine circulating levels of VEGF, VEGFR-1, PIGF, PDGF-AA, PDGF-BB, Ang-1 and EGF. Multivariate analyses on cancerspecific survival were performed with a Cox proportional hazards model.

Results: VEGF ( $p<0.0001)$, PDGF-AA ( $p<0.0001)$, Ang-1 ( $p=0.002)$ and EGF $(p<0.0001)$ were differentially expressed in patients with pancreatic cancer compared to healthy controls. The presence of lymph node metastases was associated with increased levels of all CAC except for PIGF, whereas there were only minor associations of CAC with other clinicopathologic variables. The multivariate model including the entire angiogenic panel revealed high levels of circulating PDGF-AA (hazard ratio 4.58; 95\% confidence interval 1.43 - 14.69) as predictor of poor cancer-specific survival, whereas high levels of PDGF-BB (0.15; $0.15-0.88)$, Ang-1 (0.30; $0.10-0.93)$ and VEGF $(0.24 ; 0.09-0.57)$ were associated with a favorable prognosis.
\end{abstract}

Conclusion: Circulating levels of certain angiogenic cytokines correlate with patients' prognosis after resection for pancreatic cancer, if a panel of several CAC is considered simultaneously. These data should be considered in future studies evaluating angiogenic factors as prognostic biomarkers and therapeutic targets in patients with pancreatic cancer.

\section{Background}

Pancreatic cancer is ranked within the ten most common malignancies in both genders, yet it is responsible for one forth of cancer-related deaths in Western countries [1]. The poor prognosis of this disease is reflected by a dismal overall 5 -year survival rate of less than $5 \%$. Surgical resection is the only treatment modality providing a chance for cure and together with adjuvant chemotherapy may improve 5 -year survival rates to 18 $25 \%$ [2-4]. Similar to other solid malignancies the majority of patients with pancreatic cancer die of tumor progression and ultimately metastatic disease. It has

\footnotetext{
* Correspondence: nuh.rahbari@med.uni-heidelberg.de

'Department of General, Visceral and Transplant Surgery, University of Heidelberg, Heidelberg, Germany

Full list of author information is available at the end of the article
}

become a well-established notion in tumor biology that tumor growth and progression to metastatic disease are dependent on the process of angiogenesis, i.e. the formation of new vasculature. More than 30 years ago, Folkman already postulated that adequate supply of oxygen and nutrients in tumors beyond a size of $2-3$ $\mathrm{mm}^{3}$ requires new blood vessels (i.e. perfusion), as it may not be achieved by diffusion alone [5]. The critical impact of angiogenesis for disease progression in solid tumors has been proven by data from experimental studies[6] together with the results of clinical trials that demonstrated a therapeutic effect of anti-angiogenic treatment in patients with colorectal cancer [7] and non-small-cell lung cancer [8].

The role of angiogenesis for disease progression in patients with pancreatic cancer has, however, remained

\section{Biomed Central}


less clear, as has been the potential effectiveness of antiangiogenic therapy for this disease $[9,10]$. Pancreatic cancers are not grossly vascularized tumors and are rather characterized by a dense stromal reaction that might in turn promote tumor invasion [11]. Intriguingly, most pancreatic cancers display overexpression of angiogenic molecules including the vascular endothelial growth factor (VEGF) as the key mediator of tumor angiogenesis [12-14]. Nonetheless, controlled clinical trials on bevacizumab, a monoclonal antibody against VEGF and Cetuximab, a monoclonal antibody against epidermal growth factor receptor (EGFR), failed to demonstrate a survival benefit of anti-angiogenic therapy for patients with pancreatic cancer $[15,16]$. The failure of these agents in therapeutic trials for pancreatic cancer may in part be related to their mode of action targeting one certain molecule or its receptor. Although angiogenesis is a highly complex process that results from a misbalance of various pro- and antiangiogenic mediators $[17,18]$, studies on the molecular biology underlying angiogenesis and the prognostic value of angiogenic cytokines in pancreatic cancer have been limited to a single or a few molecules.

Angiogenic cytokines are soluble molecules and their levels in systemic circulation may reflect the overall angiogenic activity of the tumor. Several studies could indeed demonstrate circulating angiogenic cytokines as prognostic biomarkers in patients with various solid tumors [19-22]. In the present study, we investigated the expression of CACs in patients undergoing surgery for pancreatic cancer and compared these CAC levels to the angiogenic profiles of patients with metastatic and benign pancreatic diseases. The selection of these cytokines was based on their known key roles in tumor angiogenesis[23-25]. Furthermore, we evaluated the prognostic significance of this angiogenic profile consisting of seven CACs in patients with primary pancreatic cancer.

\section{Methods}

The primary study cohort comprised 74 patients who underwent resection for primary pancreatic cancer at the Department of General, Visceral and Transplantation Surgery, University of Heidelberg between November 2006 and April 2008. These patients had the histological diagnosis of pancreatic ductal adenocarcinoma and underwent R0 or R1 resection. Patients who received neoadjuvant chemoradiotherapy were excluded from the analysis, as were patients with a history of a second malignancy. Furthermore, we excluded patients with tumors that developed on the basis of intraductal papillary mucinous neoplasms or mucinous cystic neoplasms. To evaluate the angiogenic profile associated with metastatic disease and benign pancreatic disease, we also enrolled 24 patients who had synchronous distant metastases revealed at exploratory laparotomy and 20 patients with chronic pancreatitis who underwent surgical resection. A further control group $(\mathrm{n}=48)$ included healthy subjects who had no evidence of acute or chronic disease and had no surgery within the past 12 months. All participants gave written informed consent. The study protocol was approved by the Ethics Committee of the University of Heidelberg.

Patients were treated as described previously [26]. Pathological specimens were processed using a standardized protocol [27]. R1 resection was defined, if the distance of the tumor from the resection margin was $\leq$ $1 \mathrm{~mm}$. Adjuvant chemotherapy with gemcitabine or 5-FU was recommended to all patients who were able to tolerate it regardless of resection margin status and tumor stage. Postoperative surveillance was performed at our outpatient clinics and the European Pancreas Center (EPC). Follow-up visits were scheduled every three months in the first two years and every six months thereafter. A clinical examination, abdominal ultrasound and routine laboratory testing with evaluation of carbohydrate antigen 19-9 (CA19-9) levels were carried out at each follow-up visit. A CT scan was performed at three months postoperatively and every 6 months thereafter. To obtain follow-up information on those patients who were not followed at our institution we contacted the primary care physicians.

\section{Serum preparation and cytokine detection}

On the day of surgery ten milliliter serum separator tubes were used to collect blood samples through a central venous catheter immediately before incision. To prevent dilution with blocking saline, the first $5-7 \mathrm{ml}$ of the drawn blood were discarded. The blood samples were then centrifuged at $2.500 \times \mathrm{g}$ for 10 minutes to extract the serum; the serum was stored at $-80^{\circ} \mathrm{C}$ until analysis. Samples of the control subjects were obtained via a peripheral vein and then processed as described above. Serum concentrations of soluble vascular endothelial growth factor receptor 1 (sVEGFR-1), placental growth factor (PlGF), platelet-derived endothelial growth factors AA (PDGF-AA), epidermal growth factor (EGF) and Angiopoetin-1 (Ang-1) were quantified using commercially available quantitative sandwich enzymelinked immunosorbent assay (ELISA) kits (Quantikine; R\&D Systems, Inc, Minneapolis, MN). All samples were analyzed in duplicate and processed at the first freezethaw cycle. Optical densities were quantified using a microtiter plate reader (ELISA Reader 2010, Anthos Mikrosysteme GmbH, Krefeld, Germany). The serum concentrations of vascular endothelial growth factor (VEGF) and platelet-derived endothelial growth factors 
BB (PDGF-BB) were determined using multiplex protein arrays (BioRad Laboratories, Hercules, CA, USA) and a two-laser array reader that simultaneously quantifies the cytokines of interest. To ensure sufficient power for subsequent survival analyses the number of included CAC was restricted to seven factors. Standard curves and concentrations were calculated using Bio-Plex Manager 4.1.1.

\section{Statistical analyses}

Continuous data were presented as median and interquartile range and were compared using the MannWhitney $U$ test. Categorical data were expressed as absolute and relative frequencies. A Spearman correlation coefficient $\geq 0.4$ was considered to indicate a relevant correlation. Cancer-specific survival was calculated from the date of surgery for pancreatic cancer to the date of death from pancreatic cancer or the date of last follow-up information. Patients who were alive at the date of last contact were censored, as were those patients who were lost to follow-up and those who died of reasons not related to the disease. Survival curves were constructed according to the Kaplan-Meier method. The log-rank test was used for univariate comparisons of time-to-event distributions. Multivariate analyses were performed using Cox proportional hazards regression analyses. To evaluate independent prognostic associations of the individual CAC the entire panel was included in the multivariate model (i.e. regardless of their associations with survival on univariate analyses). In addition, clinicopathologic variables with a $\mathrm{p}$-value $<0.2$ on univariate analyses were included in the multivariate model. The levels of CAC were dichotomized using the median value. All $\mathrm{p}$ values were two-sided and a p-value $\leq 0.05$ was considered statistically significant. All analyses were performed using SPSS ${ }^{\circledR}$ software version 17 (SPSS, Chicago, Illinois, USA) and JMP program version 7 (SAS Institute Inc., Cary, NC, USA).

\section{Results}

Table 1 summarizes the clinicopathologic characteristics of the 74 patients who underwent surgical resection for pancreatic cancer. There were 37 (50\%) men and 37 women with a median age of 67.1 (58.7 - 70.7) years. The majority of patients had a tumor located in the pancreatic head $(\mathrm{n}=54 ; 73 \%)$, whereas $14(19 \%)$ and $6(8 \%)$ patients had tumors located in the body and tail of the pancreas, respectively. Final pathological examination revealed lymph node metastases in 54 (73\%) patients and microscopic margin involvement in 47 (64\%) patients. Poorly differentiated tumors were diagnosed in $22(31 \%)$ patients. A total of 49 (66\%) patients received adjuvant therapy. Details on the applied

Table 1 Clinicopathologic characteristics of the study population

\begin{tabular}{lc}
\hline & $\mathbf{n}(\%)$ or median (IQR) \\
\hline Total, $\mathbf{n}$ & $\mathbf{7 4}(\mathbf{1 0 0 )}$ \\
\hline Gender & \\
Male & $37(50.0)$ \\
Female & $37(50.0)$
\end{tabular}

Age [years]

$67.1(58.7-70.7)$

\section{Location of the tumor \\ Pancreatic head \\ Pancreatic body \\ Pancreatic tail}

CEA level $[\mu \mathrm{g} / \mathrm{l}]$

CA 19-9 level $[\mu \mathrm{g} / \mathrm{l}]$

Tumor size

$\mathrm{T} 1 / 2$

$\mathrm{T} 3$

Lymph node status

Positive

Negative

$54(73.0)$

$20(27.0)$

\section{Resection margin status}

RO

R1

$27(36.5)$

47 (63.5)

\section{Tumor differentiation}

Moderate (G2) 48 (68.6)

Poor (G3) $22(31.4)$
Adjuvant therapy

Yes $49(66.2)$

No 25 (33.8)

CEA, Carcinoembryonic antigen; CA, carbohydrate antigen; IQR, Interquartile range

adjuvant chemotherapy protocols are provided in Additional file 1 .

\section{Expression of circulating angiogenic cytokines in pancreatic cancer and control groups}

In patients with primary pancreatic cancer, circulating levels of VEGF ( $p<0.0001)$ were significantly increased compared to healthy control subjects, whereas circulating levels of PDGF-AA ( $\mathrm{p}<0.0001)$, Ang-1 ( $\mathrm{p}=0.002)$ and EGF $(\mathrm{p}<0.0001)$ were significantly decreased. The comparison of the circulating angiogenic profile of patients with pancreatic cancer and chronic pancreatitis 
as benign control revealed significantly higher levels of VEGF $(p=0.05)$ and lower levels of PDGF-AA $(p<0.0001)$ in patients with malignant disease. The difference in PDGF-BB levels failed to reach statistical significance in the comparison of primary pancreatic cancer patients with healthy subjects $(\mathrm{p}=0.07)$ and patients with chronic pancreatitis $(\mathrm{p}=0.08)$. Certain CAC were differentially expressed in patients with primary and metastatic pancreatic cancer. While circulating levels of PlGF $(\mathrm{p}=0.003)$ and PDGF-AA $(\mathrm{p}=0.02)$ were significantly higher in patients with metastatic disease, these patients had lower serum concentrations of PDGF-BB ( $\mathrm{p}=0.001)$ (Figure 1).

\section{Correlation of CAC in patients with primary pancreatic cancer}

The results of the correlation analyses are displayed in Table 2. There was no correlation between circulating levels of VEGFR-1 and PIGF with those of other angiogenic cytokines in patients with primary pancreatic cancer. However, we found positive correlations of PDGF-AA and Ang-1 with several CAC: PDGF-AA levels correlated with VEGF $(r=0.437)$, PDGF-BB $(\mathrm{r}=0.450)$, Ang-1 $(\mathrm{r}=0.755)$ and EGF $(\mathrm{r}=0.429)$ levels. Circulating levels of Ang-1 correlated with VEGF $(r=0.401)$, PDGF-BB $(r=0.491)$ and EGF $(r=$ 0.578).

\section{Association of CAC with clinicopathologic parameters in patients with primary pancreatic cancer}

In a further analysis we evaluated, if circulating levels of angiogenic cytokines were associated with clinical and pathologic variables of patients with pancreatic cancer (Table 3). The results of these analyses show these associations to be rather moderate. The presence of lymph node metastases, however, correlated with increased levels of several CAC such as VEGF ( $p=0.02)$, VEGFR$1(\mathrm{p}=0.006)$, PDGF-AA $(\mathrm{p}=0.04)$, PDGF-BB $(\mathrm{p}=$ $0.0008)$, Ang-1 ( $p=0.004)$ and EGF $(p=0.03)$.

\section{Prognostic significance of CAC in patients with primary pancreatic cancer}

Patients were followed for a median duration of 19.4 months. A total of 33 (45\%) patients died of their disease during the follow-up period and 7 (9\%) patients were lost to follow-up. These patients were censored at the date they were lost to follow-up.

To investigate general clinical and pathologic variables that are associated with survival after resection for pancreatic cancer, we initially performed univariate analyses (Table 4). These analyses revealed poor tumor differentiation ( $p=0.02$; log-rank test) to be associated with an unfavorable prognosis, whereas the association of positive lymph node status ( $\mathrm{p}=0.13$; log-rank test) and R1 resection status $(\mathrm{p}=0.08$; log-rank test) with survival

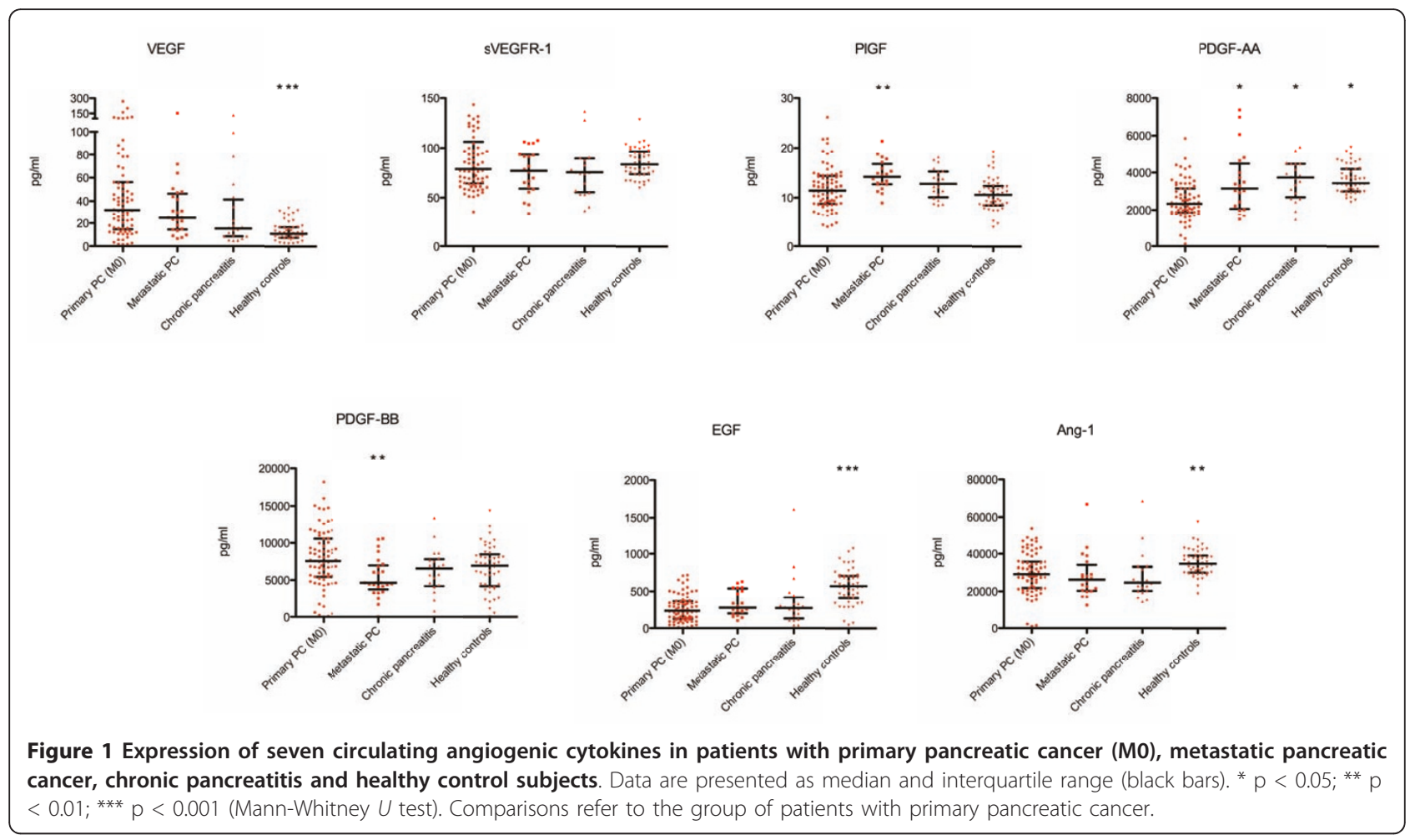


Table 2 Correlation of circulating angiogenic cytokines in patients with primary pancreatic cancer

\begin{tabular}{|c|c|c|c|c|c|c|c|}
\hline & VEGF & VEGFR-1 & PIGF & PDGF-A & PDGF-B & Ang-1 & EGF \\
\hline \multirow[t]{2}{*}{ VEGF } & 1 & 0.135 & 0.234 & 0.437 & 0.275 & 0.401 & 0.271 \\
\hline & & 0.25 & 0.04 & $<0.0001$ & 0.02 & 0.0005 & 0.02 \\
\hline \multirow[t]{2}{*}{ VEGFR-1 } & 0.135 & 1 & 0.164 & 0.201 & 0.270 & 0.292 & 0.066 \\
\hline & 0.25 & & 0.16 & 0.08 & 0.02 & 0.01 & 0.57 \\
\hline \multirow[t]{2}{*}{ PIGF } & 0.234 & 0.164 & 1 & 0.299 & 0.229 & 0.153 & 0.134 \\
\hline & 0.04 & 0.16 & & 0.01 & 0.05 & 0.19 & 0.25 \\
\hline \multirow[t]{2}{*}{ PDGF-A } & 0.437 & 0.201 & 0.299 & 1 & 0.450 & 0.755 & 0.429 \\
\hline & $<0.0001$ & 0.08 & 0.01 & & $<0.0001$ & $<0.0001$ & 0.0001 \\
\hline \multirow[t]{2}{*}{ PDGF-B } & 0.275 & 0.270 & 0.229 & 0.450 & 1 & 0.491 & 0.206 \\
\hline & 0.02 & 0.02 & 0.05 & $<0.0001$ & & $<0.0001$ & 0.08 \\
\hline \multirow[t]{2}{*}{ Ang-1 } & 0.401 & 0.292 & 0.153 & 0.755 & 0.491 & 1 & 0.578 \\
\hline & 0.0005 & 0.01 & 0.19 & $<0.0001$ & $<0.0001$ & & $<0.0001$ \\
\hline \multirow[t]{2}{*}{ EGF } & 0.271 & 0.066 & 0.134 & 0.429 & 0.206 & 0.578 & 1 \\
\hline & 0.02 & 0.57 & 0.25 & 0.0001 & 0.08 & $<0.0001$ & \\
\hline
\end{tabular}

The upper value indicates Spearman's correlation coefficient, whereas the lower value indicates the p-value. Relevant correlations are highlighted in bold figures.

failed to reach statistical significance. On exploratory, univariate analyses none of the individual CAC was associated with patients' prognosis.

We next constructed a multivariate Cox proportional hazards model to assess the prognostic value of our panel of CAC in patients undergoing resection for pancreatic cancer. Using the median values to dichotomize single CAC, this model included the entire panel of CAC together with clinicopathologic variables that had a prognostic value on univariate analyses. The results of this analysis revealed high levels of circulating PDGFAA as adverse prognostic factor with respect to cancerspecific survival (hazard ratio 4.58; $95 \%$ confidence interval $1.43-14.69 ; \mathrm{p}=0.01$ ). Furthermore, this

Table 3 Association of circulating angiogenic factors with clinicopathologic variables in patients with primary pancreatic cancer

\begin{tabular}{|c|c|c|c|c|c|c|c|}
\hline & VEGF & VEGFR1 & PIGF & PDGF-A & PDGF-B & Ang-1 & EGF \\
\hline \multicolumn{8}{|l|}{ Age [years] } \\
\hline$<65$ & $\begin{array}{c}38.8 \\
(12.6,53.6)\end{array}$ & $\begin{array}{c}86.7 \\
(65.6,121.9)\end{array}$ & $\begin{array}{c}11.6 \\
(9.7,14,7)\end{array}$ & $\begin{array}{c}2349.2 \\
(1971.9,3214.9)\end{array}$ & $\begin{array}{c}7823.3 \\
(5763.4,10002.4)\end{array}$ & $\begin{array}{c}32082.5 \\
(27097.9,40061.8)\end{array}$ & $\begin{array}{c}261.4 \\
(137.3,404.4)\end{array}$ \\
\hline$\geq 65$ & $\begin{array}{c}30.3 \\
(15.8,67.8)\end{array}$ & $\begin{array}{c}76.2 \\
(63.2,102.8)\end{array}$ & $\begin{array}{c}11.3 \\
(8.6,13.9)\end{array}$ & $\begin{array}{c}2256.1 \\
(1805.9,3159.1)\end{array}$ & $\begin{array}{c}7624.3 \\
(4909.1,11280.5)\end{array}$ & $\begin{array}{c}27874.6 \\
(20839.6,34988.1)\end{array}$ & $\begin{array}{c}229.3 \\
(122.1,339.6)\end{array}$ \\
\hline \multicolumn{8}{|l|}{ Gender } \\
\hline Male & $\begin{array}{c}33.7 \\
(12.6,54.1)\end{array}$ & $\begin{array}{c}76.5 \\
(64.3,98.5)\end{array}$ & $\begin{array}{c}12.1 \\
(9.4,14.6)\end{array}$ & $\begin{array}{c}2329.9 \\
(1913.3,3286.0)\end{array}$ & $\begin{array}{c}7461.2 \\
(5336.6,11665.4)\end{array}$ & $\begin{array}{c}29589.7 \\
(23901.5,39920.1)\end{array}$ & $\begin{array}{c}276.1 \\
(152.5,356.3)\end{array}$ \\
\hline Female & $\begin{array}{c}29.8 \\
(15.6,59.0)\end{array}$ & $\begin{array}{c}85.6 \\
(63.3,123.3)\end{array}$ & $\begin{array}{c}11.3 \\
(7.8,14.1)\end{array}$ & $\begin{array}{c}2342.7 \\
(1798.8,3162.7)\end{array}$ & $\begin{array}{c}7691.8 \\
(5627.9,9768.8)\end{array}$ & $\begin{array}{c}28157.4 \\
(21420.4,34759.1)\end{array}$ & $\begin{array}{c}185.1 \\
(102.3,373.2)\end{array}$ \\
\hline \multicolumn{8}{|c|}{ CA 19-9 level $[\mu \mathrm{g} / \mathrm{l}]$} \\
\hline$<37$ & $\begin{array}{c}29.2 \\
(13.9,47.9)\end{array}$ & $\begin{array}{c}76.6 \\
(68.7,99.2)\end{array}$ & $\begin{array}{c}10.0 \\
(7.4,14.8)\end{array}$ & $\begin{array}{c}2224.5 \\
(1889.7,3077.1)\end{array}$ & $\begin{array}{c}7685.5 \\
(5662.1,9890.9)\end{array}$ & $\begin{array}{c}25991.6 \\
(20353.1,31308.6)\end{array}$ & $\begin{array}{c}197.7 \\
(92.6,283.8)\end{array}$ \\
\hline$\geq 37$ & $\begin{array}{c}36.9 \\
(13.9,73.3)\end{array}$ & $\begin{array}{c}79.0 \\
(63.3,114.2)\end{array}$ & $\begin{array}{c}12.1 \\
(9.3,14.3)\end{array}$ & $\begin{array}{c}2342.7 \\
(1840.9,3342.9)\end{array}$ & $\begin{array}{c}7556.8 \\
(4851.8,10790.6)\end{array}$ & $\begin{array}{c}30517.1 \\
(22698.9,39237.5)\end{array}$ & $\begin{array}{c}283.4 \\
(130.6,400.7)\end{array}$ \\
\hline \multicolumn{8}{|c|}{ Lymph node status } \\
\hline Positive & $\begin{array}{c}39.6 \\
(17.4,68.7)^{*}\end{array}$ & $\begin{array}{c}84.3 \\
(68.9,120.7)^{\S}\end{array}$ & $\begin{array}{c}12.1 \\
(9.3,14.4)\end{array}$ & $\begin{array}{c}2370.2 \\
(1888.7,3417.9)^{*}\end{array}$ & $\begin{array}{c}8658.4 \\
(6787.3,11406.9)^{\#}\end{array}$ & $\begin{array}{c}30907.3 \\
(25670.3,41267.9)^{\S}\end{array}$ & $\begin{array}{c}286.1 \\
(146.8,391.3)^{*}\end{array}$ \\
\hline negative & $\begin{array}{c}21.3 \\
(8.3,40.7)\end{array}$ & $\begin{array}{c}67.2 \\
(56.9,85.1)\end{array}$ & $\begin{array}{c}10.2 \\
(8.2,14.3)\end{array}$ & $\begin{array}{c}2096.8 \\
(1795.8,2623.6)\end{array}$ & $\begin{array}{c}5627.9 \\
(4566.7,7215.9)\end{array}$ & $\begin{array}{c}24700.5 \\
(16330.9,31600.9)\end{array}$ & $\begin{array}{c}171.6 \\
(84.1,253.2)\end{array}$ \\
\hline \multicolumn{8}{|c|}{ Tumor differentiation } \\
\hline $\begin{array}{l}\text { Moderate } \\
(G 2)\end{array}$ & $\begin{array}{c}31.6 \\
(12.8,55.3)\end{array}$ & $\begin{array}{c}78.8 \\
(63.1,119.7)\end{array}$ & $\begin{array}{c}10.6 \\
(8.5,13.7)\end{array}$ & $\begin{array}{c}2336.3 \\
(1869.7,2850.1)\end{array}$ & $\begin{array}{c}7693.9 \\
(5448.5,10587.1)\end{array}$ & $\begin{array}{c}28568.6 \\
(21839.1,34451.8)\end{array}$ & $\begin{array}{c}224.8 \\
(133.4,333.3)\end{array}$ \\
\hline $\begin{array}{l}\text { Poor } \\
\text { (G3) }\end{array}$ & $\begin{array}{c}39.0 \\
(21.2,66.7)\end{array}$ & $\begin{array}{c}80.4 \\
(67.7,100.6)\end{array}$ & $\begin{array}{c}12.6 \\
(10.1,15.8)\end{array}$ & $\begin{array}{c}2561.1 \\
(1853.7,3491.3)\end{array}$ & $\begin{array}{c}7756.3 \\
(4608.0,11545.1)\end{array}$ & $\begin{array}{c}33120.3 \\
(22580.3,40538.4)\end{array}$ & $\begin{array}{c}282.5 \\
(112.2,472.8)\end{array}$ \\
\hline
\end{tabular}

Value are expressed as median (interquartile range) and compared using the Mann-Whitney $U$ test; $\mathrm{CA}$, carbohydrate antigen; ${ }^{*} \mathrm{p}<0.05 ;{ }^{\S} \mathrm{p}<0.01 ;{ }^{\#} \mathrm{p}<0.001$ 
Table 4 Association of clinicopathologic variables and circulating angiogenic cytokines with cancer-specific survival: univariate analyses

\begin{tabular}{|c|c|c|c|}
\hline & n (\%) & $\begin{array}{l}\text { Cancer-specific } \\
\text { survival n (\%) }\end{array}$ & $P$ Value* \\
\hline Total & $74(100)$ & - & - \\
\hline Gender & & & 0.72 \\
\hline Male & $37(50.0)$ & $19(51.3)$ & \\
\hline Female & $37(50.0)$ & $14(37.8)$ & \\
\hline Age [years] & & & 0.22 \\
\hline$<65$ & $30(40.5)$ & $14(46.7)$ & \\
\hline$\geq 65$ & $44(59.5)$ & $19(43.2)$ & \\
\hline Location of the tumor & & & 0.74 \\
\hline Pancreatic head & $54(73.0)$ & $25(46.3)$ & \\
\hline Pancreatic body & $14(18.9)$ & $4(28.6)$ & \\
\hline Pancreatic tail & $6(8.1)$ & $4(66.7)$ & \\
\hline CA 19-9 level & & & 0.38 \\
\hline$<37[\mu \mathrm{g} / \mathrm{l}]$ & $20(27.4)$ & $8(40.0)$ & \\
\hline$\geq 37[\mu \mathrm{g} / \mathrm{l}]$ & $53(72.6)$ & $25(47.2)$ & \\
\hline CEA level & & & 0.59 \\
\hline$<2.5[\mu \mathrm{g} / \mathrm{l}]$ & $33(45.2)$ & $14(42.4)$ & \\
\hline$\geq 2.5[\mu \mathrm{g} / \mathrm{l}]$ & $40(54.8)$ & $19(47.5)$ & \\
\hline Lymph node status & & & 0.13 \\
\hline No & $54(73.0)$ & $26(48.1)$ & \\
\hline $\mathrm{N} 1$ & $20(27.0)$ & $7(35.0)$ & \\
\hline Tumor differentiation & & & 0.02 \\
\hline Moderate (G2) & $48(68.6)$ & $20(41.7)$ & \\
\hline Poor (G3) & $22(31.4)$ & $12(54.5)$ & \\
\hline Resection margin status & & & 0.08 \\
\hline RO & $27(36.5)$ & $8(29.6)$ & \\
\hline R1 & $47(63.5)$ & $25(53.2)$ & \\
\hline VEGF & & & 0.19 \\
\hline$\geq 32.1$ & $37(50.0)$ & $14(37.8)$ & \\
\hline$<32.1$ & $37(50.0)$ & $19(51.3)$ & \\
\hline VEGFR-1 & & & 0.51 \\
\hline$\geq 78.5$ & $37(50.0)$ & $15(40.5)$ & \\
\hline$<78.5$ & $37(50.0)$ & 18 (48.6) & \\
\hline PIGF & & & 0.84 \\
\hline$\geq 11.4$ & $37(50.0)$ & $18(48.6)$ & \\
\hline$<11.4$ & $37(50.0)$ & $15(40.5)$ & \\
\hline PDGF-AA & & & 0.53 \\
\hline$\geq 2336.3$ & $37(50.0)$ & $19(51.3)$ & \\
\hline$<2336.3$ & $37(50.0)$ & $14(37.8)$ & \\
\hline PDGF-BB & & & 0.10 \\
\hline$\geq 7624.3$ & $37(50.0)$ & $13(35.1)$ & \\
\hline$<7624.3$ & $37(50.0)$ & $20(54.1)$ & \\
\hline Ang-1 & & & 0.53 \\
\hline$\geq 29202.1$ & $37(50.0)$ & $15(40.5)$ & \\
\hline$<29202.1$ & $37(50.0)$ & $18(48.7)$ & \\
\hline EGF & & & 0.26 \\
\hline$\geq 234.2$ & $37(50.0)$ & $17(45.9)$ & \\
\hline$<234.2$ & $37(50.0)$ & $16(43.2)$ & \\
\hline
\end{tabular}

* log-rank test; CEA, Carcinoembryonic antigen; CA, carbohydrate antigen. analysis demonstrated high circulating levels of VEGF (HR 0.24; 95\% CI 0.09 - 0.57; p = 0.002), PDGF-BB (HR 0.15 ; 95\% CI $0.15-0.88 ; \mathrm{p}=0.02)$ and Ang-1 (HR 0.30; $95 \%$ CI $0.10-0.93 ; \mathrm{p}=0.04$ ) of being associated with a favorable prognosis (Table 5). Figure 2 shows the Kaplan-Meier plots of CAC that had significant associations with cancer-specific survival on multivariate analyses.

\section{Discussion}

The present study provides a comprehensive analysis of the expression and prognostic associations of CAC in patients with pancreatic cancer. Including a panel of seven CAC, the results show that certain CAC such as VEGF, PDGF-AA, Ang-1 and EGF are differentially expressed in patients with pancreatic cancer compared to healthy subjects. Furthermore, we found correlations among CAC in these patients, in particular to PDGFAA and Ang-1. Except for PlGF the levels of all CAC, moreover, correlated with the presence of lymph node metastases, whereas there were very little associations with other clinicopathologic variables. Although the expression of individual CAC did not correlate with patients' survival on univariate analyses, the multivariate model including all angiogenic factors revealed that serum levels of VEGF, PDGF-AA, PDGF-BB and Ang-1 correlate with patients' prognosis, if the whole panel of seven CAC is considered.

The formation of new vasculature is a complex process that is mediated by a variety of cytokines [6].

Table 5 Multivariate analysis of factors associated with cancer-specific survival

\begin{tabular}{|c|c|c|c|c|}
\hline Variable & Category & $\begin{array}{c}\text { Hazard } \\
\text { ratio }\end{array}$ & $\begin{array}{c}95 \% \\
\text { confidence } \\
\text { interval }\end{array}$ & $\begin{array}{c}P \\
\text { value* }^{*}\end{array}$ \\
\hline $\begin{array}{l}\text { Resection } \\
\text { margin status }\end{array}$ & R1 vs. R0 & 1.86 & $0.69-5.04$ & 0.22 \\
\hline $\begin{array}{l}\text { Lymph node } \\
\text { status }\end{array}$ & $\begin{array}{c}\text { Positive vs. } \\
\text { negative }\end{array}$ & 2.09 & $0.68-6.46$ & 0.19 \\
\hline $\begin{array}{l}\text { Tumor } \\
\text { differentiation }\end{array}$ & $\begin{array}{l}\text { Poor (G3) vs. } \\
\text { moderate (G2) }\end{array}$ & 2.27 & $0.97-5.32$ & 0.06 \\
\hline VEGF $[\mathrm{pg} / \mathrm{ml}]$ & $\geq 32.1$ vs. $<32.1$ & 0.24 & $0.09-0.57$ & 0.002 \\
\hline $\begin{array}{l}\text { VEGFR-1 } \\
{[\mathrm{pg} / \mathrm{ml}]}\end{array}$ & $\geq 78.5$ vs. $<78.5$ & 1.52 & $0.63-3.64$ & 0.35 \\
\hline PIGF $[\mathrm{pg} / \mathrm{ml}]$ & $\geq 11.4$ vs. $<11.4$ & 0.87 & $0.35-2.12$ & 0.76 \\
\hline $\begin{array}{l}\text { PDGF-AA } \\
{[\mathrm{pg} / \mathrm{ml}]}\end{array}$ & $\begin{array}{c}\quad \geq 2336.3 \\
\text { vs. }<2336.3\end{array}$ & 4.58 & $1.43-14.69$ & 0.01 \\
\hline $\begin{array}{l}\text { PDGF-BB } \\
{[\mathrm{pg} / \mathrm{ml}]}\end{array}$ & $\begin{array}{c}\geq 7624.3 \text { vs. }< \\
7624.3\end{array}$ & 0.36 & $0.15-0.88$ & 0.02 \\
\hline Ang-1 $[\mathrm{pg} / \mathrm{ml}]$ & $\begin{array}{l}\quad \geq 29202.1 \\
\text { vs. }<29202.1\end{array}$ & 0.30 & $0.10-0.93$ & 0.04 \\
\hline EGF $[\mathrm{pg} / \mathrm{ml}]$ & $\begin{array}{c}\geq 234.2 \\
\text { vs. }<234.2\end{array}$ & 1.92 & $0.81-4.54$ & 0.14 \\
\hline
\end{tabular}

${ }^{*}$ Cox proportional hazards regression model 

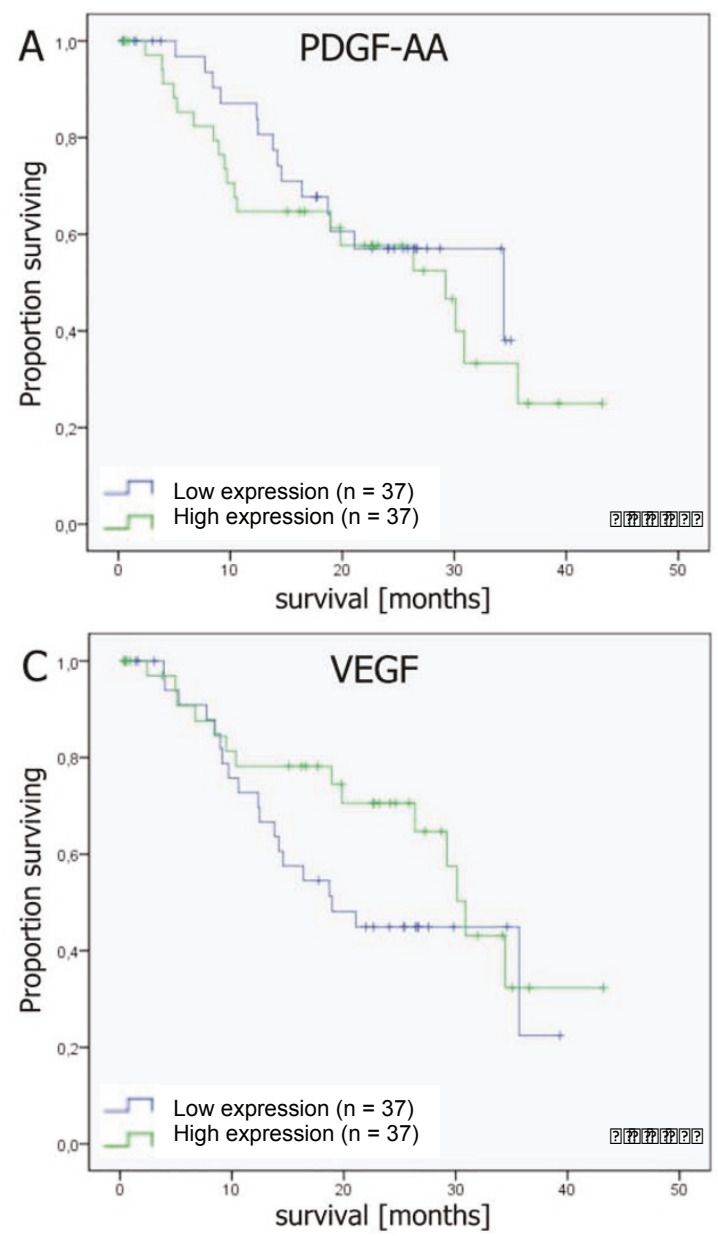
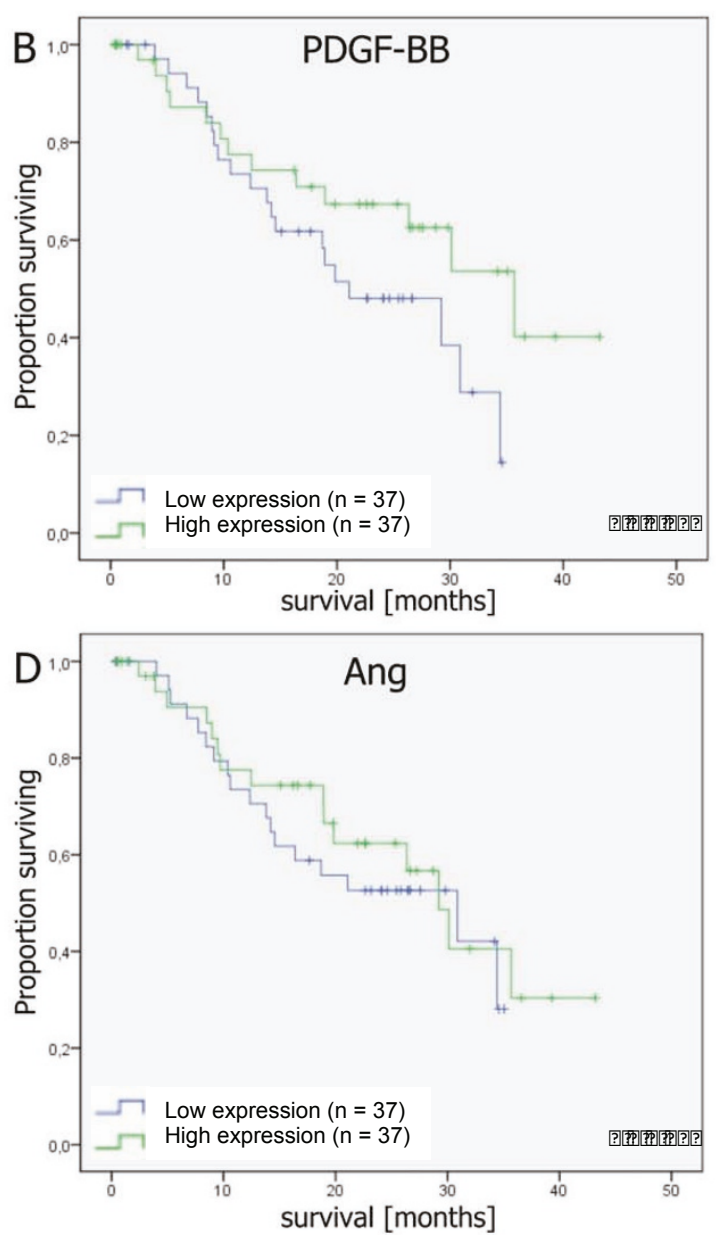

Figure 2 Kaplan-Meier plots of circulating angiogenic cytokines that had significant associations with cancer-specific survival on multivariate analyses. P-values refer to the results of univariate analyses (log-rank test).

Although continuous research on the molecular basis of tumor angiogenesis in solid human malignancies revealed various factors involved in this process, little is known about the interplay of these factors, in particular with respect to pancreatic cancer. The majority of experimental as well as translational studies have investigated expression and biological function of a single or very few angiogenic molecules. Our analyses, however, show multiple correlations between the different angiogenic cytokines and thus suggest that their biological functions in vivo should not be considered independently of each other, as should not be their utility in clinical practice. This notion is supported by the finding that none of the analyzed CAC correlated with patients' prognosis on univariate analyses, whereas four of these factors were significantly associated with survival on multivariate analysis including all angiogenic cytokines together with known clinicopathologic prognostic factors.

Owing to the fundamental role of angiogenesis for the growth and metastatic progression of tumors, angiogenic cytokines have been proposed as targets for systemic therapy. Furthermore, they may serve as biomarkers to predict the response or resistance to chemotherapy or anti-angiogenic therapy $[28,29]$. To date, however, there is no validated biological marker to accurately select cancer patients for systemic therapy [28]. One should consider that the majority of available studies did not investigate a panel of markers. Together with these data our findings suggest that the lack of one single predictive biomarker may be due to the complex interaction and involvement of various factors and due to a strong biologic and prognostic correlation between these factors. In a recently published study, Kopetz et al. examined changes of various circulating cytokines in 43 patients receiving anti-angiogenic therapy with bevacizumab for metastatic colorectal cancer and found several of these factors to be increased prior to radiological development of progressive disease [30]. While these data also indicate that the assessment of multiple factors provides more accurate information, further studies are 
required to validate these findings and to confirm them in other types of malignancies.

Although the lack of studies assessing multiple angiogenic factors holds true for most solid tumors, it might be of particular interest in pancreatic cancer owing to the controversial role of angiogenesis in this disease. Despite its aggressive behavior and the known overexpression of angiogenic factors, pancreatic cancer is not a strongly vascularized tumor. In line with previous studies [12-14] our data demonstrated VEGF, a key regulator of tumor angiogenesis [31], to be overexpressed in patients with pancreatic cancer. The exact biological role of VEGF and its interplay with other angiogenic cytokines in pancreatic cancer remains poorly understood and the value of VEGF as predictor of outcome in patients with pancreatic cancer is controversial [12,14,32-36]. Our finding of an inverse correlation of circulating VEGF levels with outcome is contradictory to studies that reported a positive correlation of VEGF levels with patients' survival and may in part be explained by differences in methodology. Some of these studies included patients with overt metastases, did not confirm this finding by multivariate analysis and examined expression of VEGF in tissue samples. Most importantly, the prognostic value of VEGF was commonly assessed independently of other CAC. Our data, however, indicate an inverse prognostic value of circulating VEGF in case further angiogenic cytokines are considered and, moreover, suggest that in pancreatic cancer angiogenesis is driven less strongly by VEGF but by alternative cytokines. This hypothesis is further supported by the results of clinical trials in patients with this disease that demonstrated moderate to low activity $[37,38]$ and failed to demonstrate a survival benefit of anti-VEGF therapy [15].

Our analyses back the role of PDGFs in the molecular biology of angiogenesis in pancreatic cancer. The PDGF signaling pathway includes four ligands (PDGF-A, -B, $-C,-D)$ and two receptors (PDGFR- $\alpha$ and $-\beta$ ) that act as dimers and are involved in various physiological functions in embryonic development and wound healing [39]. While experimental data show PDGF signaling also to be involved in tumor growth, angiogenesis and metastasis of various cancers including pancreatic cancer [40-43], there is limited data on its biological relevance in humans. We here show that circulating PDGF-AA correlates with circulating levels of several angiogenic factors and high levels of circulating PDGFAA are associated with poor survival in patients with pancreatic cancer and thus confirm data showing that high PDGF-AA mRNA expression levels in pancreatic tumors are correlated to shorted survival [36]. While PDGF-AA expression has already been shown to correlate with poor prognosis in other tumor entities [44,45], we also found an inverse correlation of circulating PDGF-BB levels with patients' survival. This finding is in line with experimental studies that demonstrated PDGF-BB overexpression to inhibit tumor growth in pancreatic and colorectal tumor models by increasing the pericyte content of the tumor microenvironment $[46,47]$. The opposed effects of PDGF-AA and PDGF$\mathrm{BB}$ on tumor progression in pancreatic cancer is also supported by our finding that these cytokines are upand down-regulated in patients with metastatic disease compared to patients with primary pancreatic cancer.

Ang-1 and Ang-2 are the two major ligands of the endothelial cell-specific tyrosine kinase receptor Tie-2. It is generally accepted that Ang-1 and 2 have important functions in the development and stabilization of vasculature $[48,49]$, though their exact role in tumor angiogenesis and progression remains incompletely understood [50,51]. This may in part may be explained by the complexity of agonistic and antagonistic ligands for the same receptor that, moreover, act in concert with each other and other mediators such as VEGF [52-54]. There is, however, increasing experimental data demonstrating that overexpression of Ang-1 inhibits neovascularization and tumor growth in various tumor models by promoting vascular stabilization and maturation [55-58]. In line with these data, clinical studies on patients with colorectal and pancreatic cancer revealed decreased tissue expression of Ang-1 and increased expression of Ang-2 [59,60], which was, moreover, revealed as an adverse prognostic marker in colorectal cancer $[61,62]$. While there is limited data on the biological role of Angiopoietins in pancreatic cancer, our results also demonstrated decreased levels of circulating Ang-1 in patients with this disease. Furthermore, we show for the first time that Ang-1 levels correlate inversely with patients' prognosis and thus confirm the above preclinical data that Ang-1 inhibits tumor progression. Owing to its proposed involvement in vascular normalization by anti-angiogenic therapy [63] our data support the notion of Ang-1 as predictive biomarker of response which should be the subject of future studies.

\section{Conclusions}

The present study analyzed the expression and biological relevance of seven CAC in patients with pancreatic cancer. The results indicate that the serum levels of certain angiogenic cytokines correlate with patients' prognosis after resection for pancreatic cancer, if a panel of several CAC is considered simultaneously. Based on these data future studies on the bioloigical role of CAC should not be limited to single molecules. The inverse correlation of certain CAC with survival may indicate why anti-angiogenic therapy has failed in patients with this disease. Furthermore, the prognostic relevance of several CAC within the analyzed panel may support the notion of multi-targeted anti-angiogenic therapy in patients with pancreatic cancer. 


\section{Additional material}

Additional file 1: Applied adjuvant chemotherapy protocols. Details

on the adjuvant chemotherapy protocols of the study cohort.

\section{Acknowledgements}

There are no acknowledgements to be declared.

\section{Author details}

${ }^{1}$ Department of General, Visceral and Transplant Surgery, University of Heidelberg, Heidelberg, Germany. ${ }^{2}$ Institute for Transplant Immunology, Hannover Medical School, Hannover, Germany.

\section{Authors' contributions}

NNR, TS, CF and MK contributed to the study design. Data acquisition was carried out by NNR, TS, CF, MH and UB. NNR, TS, UH, JW and MK contributed to data analysis. NNR and MK drafted the manuscript and TS, $C F, U H M H, U B, M W B$ and JW revised the manuscript. Funding was obtained by MWB, JW and MK.

All authors read and approved the final version of the manuscript.

\section{Competing interests}

The authors declare that they have no competing interests.

Received: 8 February 2011 Accepted: 5 July 2011 Published: 5 July 2011

\section{References}

1. Jemal A, Siegel R, Xu J, Ward E: Cancer statistics, 2010. CA: A Cancer Journal for Clinicians 2010, 60(5):277-300.

2. Neoptolemos JP, Dunn JA, Stocken DD, Almond J, Link K, Beger H, Bassi C, Falconi M, Pederzoli P, Dervenis C, et al: Adjuvant chemoradiotherapy and chemotherapy in resectable pancreatic cancer: a randomised controlled trial. Lancet 2001, 358(9293):1576-1585.

3. Neoptolemos JP, Stocken DD, Friess H, Bassi C, Dunn JA, Hickey H, Beger $H$, Fernandez-Cruz L, Dervenis C, Lacaine Fo, et al: A randomized trial of chemoradiotherapy and chemotherapy after resection of pancreatic cancer. The New England Journal of Medicine 2004, 350(12):1200-1210.

4. Oettle H, Post S, Neuhaus P, Gellert K, Langrehr J, Ridwelski K, Schramm H, Fahlke J, Zuelke C, Burkart C, et al: Adjuvant chemotherapy with gemcitabine vs observation in patients undergoing curative-intent resection of pancreatic cancer: a randomized controlled trial. JAMA: The Journal of the American Medical Association 2007, 297(3):267-277.

5. Folkman J: Tumor angiogenesis: therapeutic implications. The New England Journal of Medicine 1971, 285(21):1182-1186.

6. Carmeliet P: Angiogenesis in life, disease and medicine. Nature 2005, 438(7070):932-936

7. Hurwitz H, Fehrenbacher L, Novotny W, Cartwright T, Hainsworth J, Heim W, Berlin J, Baron A, Griffing S, Holmgren E, et al: Bevacizumab plus irinotecan, fluorouracil, and leucovorin for metastatic colorectal cancer The New England Journal of Medicine 2004, 350(23):2335-2342.

8. Sandler A, Gray R, Perry MC, Brahmer J, Schiller JH, Dowlati A, Lilenbaum R, Johnson DH: Paclitaxel-carboplatin alone or with bevacizumab for nonsmall-cell lung cancer. The New England Journal of Medicine 2006, 355(24):2542-2550

9. Wong $\mathrm{HH}$, Lemoine NR: Pancreatic cancer: molecular pathogenesis and new therapeutic targets. Nature Reviews Gastroenterology \& Hepatology 2009, 6(7):412-422

10. Korc M: Pathways for aberrant angiogenesis in pancreatic cancer Molecular Cancer 2003, 2:8-8.

11. Mahadevan D, Von Hoff DD: Tumor-stroma interactions in pancreatic ductal adenocarcinoma. Molecular Cancer Therapeutics 2007 6(4):1186-1197.

12. Ikeda N, Adachi M, Taki T, Huang C, Hashida H, Takabayashi A, Sho M Nakajima $Y$, Kanehiro $H$, Hisanaga $M$, et al: Prognostic significance of angiogenesis in human pancreatic cancer. British Journal of Cancer 1999, 79(9-10):1553-1563.

13. Itakura J, Ishiwata $T$, Shen B, Kornmann M, Korc M: Concomitant overexpression of vascular endothelial growth factor and its receptors in pancreatic cancer. International Journal of Cancer Journal International Du Cancer 2000, 85(1):27-34.

14. Fujimoto K, Hosotani R, Wada M, Lee JU, Koshiba T, Miyamoto Y, Tsuji S, Nakajima S, Doi R, Imamura M: Expression of two angiogenic factors, vascular endothelial growth factor and platelet-derived endothelial cell growth factor in human pancreatic cancer, and its relationship to angiogenesis. European Journal of Cancer (Oxford, England: 1990) 1998, 34(9):1439-1447

15. Kindler $H L$, Niedzwiecki D, Hollis D, Sutherland S, Schrag D, Hurwitz $H$, Innocenti F, Mulcahy MF, O'Reilly E, Wozniak TF, et al: Gemcitabine Plus Bevacizumab Compared With Gemcitabine Plus Placebo in Patients With Advanced Pancreatic Cancer: Phase III Trial of the Cancer and Leukemia Group B (CALGB 80303). Journal of Clinical Oncology: Official Journal of the American Society of Clinical Oncology 2010, 28(22):3617-3622.

16. Philip PA, Benedetti J, Corless CL, Wong R, O'Reilly EM, Flynn PJ, Rowland KM, Atkins JN, Mirtsching BC, Rivkin SE, et al: Phase III study comparing gemcitabine plus cetuximab versus gemcitabine in patients with advanced pancreatic adenocarcinoma: Southwest Oncology Groupdirected intergroup trial S0205. J Clin Oncol 2010, 28(22):3605-3610.

17. Hanahan D, Weinberg RA: The hallmarks of cancer. Cell 2000, 100(1):57-70.

18. Sund M, Zeisberg M, Kalluri R: Endogenous stimulators and inhibitors of angiogenesis in gastrointestinal cancers: basic science to clinical application. Gastroenterology 2005, 129(6):2076-2091.

19. Ugurel S, Rappl G, Tilgen W, Reinhold U: Increased serum concentration of angiogenic factors in malignant melanoma patients correlates with tumor progression and survival. Journal of Clinical Oncology: Official Journal of the American Society of Clinical Oncology 2001, 19(2):577-583.

20. Kwon KA, Kim SH, Oh SY, Lee S, Han JY, Kim KH, Goh RY, Choi HJ, Park KJ Roh MS, et al: Clinical significance of preoperative serum vascular endothelial growth factor, interleukin-6, and C-reactive protein level in colorectal cancer. BMC Cancer 2010, 10:203-203.

21. Tsushima H, Ito N, Tamura S, Matsuda $Y$, Inada M, Yabuuchi I, Imai $Y$, Nagashima R, Misawa $H$, Takeda $H$, et al: Circulating transforming growth factor beta 1 as a predictor of liver metastasis after resection in colorectal cancer. Clinical Cancer Research: An Official Journal of the American Association for Cancer Research 2001, 7(5):1258-1262.

22. Rahbari NN, Reissfelder C, Muhlbayer M, Weidmann K, Kahlert C, Buchler MW, Weitz J, Koch M: Correlation of Circulating Angiogenic Factors with Circulating Tumor Cells and Disease Recurrence in Patients Undergoing Curative Resection for Colorectal Liver Metastases. Annals of Surgical Oncology 2011.

23. Poon RT, Fan ST, Wong J: Clinical implications of circulating angiogenic factors in cancer patients. Journal of Clinical Oncology: Official Journal of the American Society of Clinical Oncology 2001, 19(4):1207-1225.

24. Poon RT-P, Lau CP-Y, Cheung ST, Yu WC, Fan ST: Quantitative correlation of serum levels and tumor expression of vascular endothelial growth factor in patients with hepatocellular carcinoma. Cancer Research 2003, 63(12):3121-3126

25. Kerbel RS: Tumor angiogenesis. The New England Journal of Medicine 2008, 358(19):2039-2049.

26. Rahbari NN, Mollberg N, Koch M, Neoptolemos JP, Weitz Jr, Büchler MW: Surgical resection for pancreatic cancer. Pancreatic Cancer Springer, Berlin; 2010, 971-976

27. Esposito I, Kleeff Jr, Bergmann F, Reiser C, Herpel E, Friess H, Schirmacher P, Büchler MW: Most pancreatic cancer resections are R1 resections. Annals of Surgical Oncology 2008, 15(6):1651-1660.

28. Jain RK, Duda DG, Willett CG, Sahani DV, Zhu AX, Loeffler JS, Batchelor TT, Sorensen AG: Biomarkers of response and resistance to antiangiogenic therapy. Nature Reviews Clinical Oncology 2009, 6(6):327-338.

29. Ferrara N, Kerbel RS: Angiogenesis as a therapeutic target. Nature 2005, 438(7070):967-974

30. Kopetz S, Hoff PM, Morris JS, Wolff RA, Eng C, Glover KY, Adinin R, Overman MJ, Valero V, Wen S, et al: Phase II trial of infusional fluorouracil, irinotecan, and bevacizumab for metastatic colorectal cancer: efficacy and circulating angiogenic biomarkers associated with therapeutic resistance. Journal of Clinical Oncology: Official Journal of the American Society of Clinical Oncology 2010, 28(3):453-459.

31. Hicklin DJ, Ellis LM: Role of the vascular endothelial growth factor pathway in tumor growth and angiogenesis. Journal of Clinical Oncology: 
Official Journal of the American Society of Clinical Oncology 2005, 23(5):1011-1027.

32. Chung GG, Yoon HH, Zerkowski MP, Ghosh S, Thomas L, Harigopal M, Charette LA, Salem RR, Camp RL, Rimm DL, et al: Vascular endothelial growth factor, FLT-1, and FLK-1 analysis in a pancreatic cancer tissue microarray. Cancer 2006, 106(8):1677-1684.

33. Seo Y, Baba H, Fukuda T, Takashima M, Sugimachi K: High expression of vascular endothelial growth factor is associated with liver metastasis and a poor prognosis for patients with ductal pancreatic adenocarcinoma. Cancer 2000, 88(10):2239-2245.

34. Niedergethmann M, Hildenbrand R, Wostbrock B, Hartel M, Sturm W Jr, Richter A, Post S: High expression of vascular endothelial growth factor predicts early recurrence and poor prognosis after curative resection for ductal adenocarcinoma of the pancreas. Pancreas 2002, 25(2):122-129.

35. Chang YT, Chang MC, Wei SC, Tien YW, Hsu C, Liang PC, Tsao PN, Jan IS, Wong JM: Serum vascular endothelial growth factor/soluble vascular endothelial growth factor receptor 1 ratio is an independent prognostic marker in pancreatic cancer. Pancreas 2008, 37(2):145-150

36. Hoffmann AC, Mori R, Vallbohmer D, Brabender J, Klein E, Drebber U, Baldus SE, Cooc J, Azuma M, Metzger R, et al: High expression of HIF1a is a predictor of clinical outcome in patients with pancreatic ductal adenocarcinomas and correlated to PDGFA, VEGF, and bFGF. Neoplasia (New York, NY) 2008, 10(7):674-679.

37. Ko AH, Dito E, Schillinger B, Venook AP, Xu Z, Bergsland EK, Wong D, Scott J, Hwang J, Tempero MA: A phase II study evaluating bevacizumab in combination with fixed-dose rate gemcitabine and low-dose cisplatin for metastatic pancreatic cancer: is an anti-VEGF strategy still applicable? Investigational New Drugs 2008, 26(5):463-471.

38. Crane $\mathrm{CH}$, Winter $\mathrm{K}$, Regine WF, Safran H, Rich TA, Curran W, Wolff RA, Willett CG: Phase II study of bevacizumab with concurrent capecitabine and radiation followed by maintenance gemcitabine and bevacizumab for locally advanced pancreatic cancer: Radiation Therapy Oncology Group RTOG 0411. Journal of Clinical Oncology: Official Journal of the American Society of Clinical Oncology 2009, 27(25):4096-4102.

39. Andrae J, Gallini R, Betsholtz C: Role of platelet-derived growth factors in physiology and medicine. Genes \& Development 2008, 22(10):1276-1312.

40. Singh PK, Wen Y, Swanson BJ, Shanmugam K, Kazlauskas A, Cerny RL, Gendler SJ, Hollingsworth MA: Platelet-derived growth factor receptor beta-mediated phosphorylation of MUC1 enhances invasiveness in pancreatic adenocarcinoma cells. Cancer Research 2007, 67(11):5201-5210.

41. Shen J, Vil MD, Zhang H, Tonra JR, Rong LL, Damoci C, Prewett M, Deevi DS, Kearney J, Surguladze D, et al: An antibody directed against PDGF receptor beta enhances the antitumor and the anti-angiogenic activities of an anti-VEGF receptor 2 antibody. Biochemical and Biophysical Research Communications 2007, 357(4):1142-1147.

42. Kitadai Y, Sasaki T, Kuwai T, Nakamura T, Bucana CD, Hamilton SR, Fidler IJ: Expression of activated platelet-derived growth factor receptor in stromal cells of human colon carcinomas is associated with metastatic potential. International Journal of Cancer Journal International Du Cancer 2006, 119(11):2567-2574.

43. Hwang RF, Yokoi K, Bucana CD, Tsan R, Killion JJ, Evans DB, Fidler IJ: Inhibition of platelet-derived growth factor receptor phosphorylation by STI571 (Gleevec) reduces growth and metastasis of human pancreatic carcinoma in an orthotopic nude mouse model. Clinical Cancer Research: An Official Journal of the American Association for Cancer Research 2003, 9(17):6534-6544.

44. Katano M, Nakamura M, Fujimoto K, Miyazaki K, Morisaki T: Prognostic value of platelet-derived growth factor-A (PDGF-A) in gastric carcinoma. Annals of Surgery 1998, 227(3):365-371.

45. Sulzbacher I, Birner P, Trieb K, Träxler M, Lang S, Chott A: Expression of platelet-derived growth factor-AA is associated with tumor progression in osteosarcoma. Modern Pathology: An Official Journal of the United States and Canadian Academy of Pathology, Inc 2003, 16(1):66-71.

46. McCarty MF, Somcio RJ, Stoeltzing O, Wey J, Fan F, Liu W, Bucana C, Ellis LM: Overexpression of PDGF-BB decreases colorectal and pancreatic cancer growth by increasing tumor pericyte content. The Journal of Clinical Investigation 2007, 117(8):2114-2122.

47. Huang H, Bhat A, Woodnutt G, Lappe R: Targeting the ANGPT-TIE2 pathway in malignancy. Nature Reviews Cancer 2010, 10(8):575-585.

48. Suri C, McClain J, Thurston G, McDonald DM, Zhou H, Oldmixon EH, Sato TN, Yancopoulos GD: Increased vascularization in mice overexpressing angiopoietin-1. Science (New York, NY) 1998, 282(5388):468-471

49. Augustin HG, Koh GY, Thurston G, Alitalo K: Control of vascular morphogenesis and homeostasis through the angiopoietin-Tie system. Nature Reviews Molecular Cell Biology 2009, 10(3):165-177.

50. Shim WS, Teh M, Mack PO, Ge R: Inhibition of angiopoietin-1 expression in tumor cells by an antisense RNA approach inhibited xenograft tumor growth in immunodeficient mice. International Journal of Cancer Journal International Du Cancer 2001, 94(1):6-15.

51. Shim WSN, Teh M, Bapna A, Kim I, Koh GY, Mack POP, Ge R: Angiopoietin 1 promotes tumor angiogenesis and tumor vessel plasticity of human cervical cancer in mice. Experimental Cell Research 2002, 279(2):299-309.

52. Asahara T, Chen D, Takahashi T, Fujikawa K, Kearney M, Magner M, Yancopoulos GD, Isner JM: Tie2 receptor ligands, angiopoietin-1 and angiopoietin-2, modulate VEGF-induced postnatal neovascularization. Circulation Research 1998, 83(3):233-240.

53. Yuan HT, Khankin EV, Karumanchi SA, Parikh SM: Angiopoietin 2 is a partial agonist/antagonist of Tie2 signaling in the endothelium. Molecular and Cellular Biology 2009, 29(8):2011-2022.

54. Eklund L, Olsen BR: Tie receptors and their angiopoietin ligands are context-dependent regulators of vascular remodeling. Experimental Cell Research 2006, 312(5):630-641.

55. Ahmad SA, Liu W, Jung YD, Fan F, Wilson M, Reinmuth N, Shaheen RM, Bucana CD, Ellis LM: The effects of angiopoietin-1 and -2 on tumor growth and angiogenesis in human colon cancer. Cancer Research 2001, 61(4):1255-1259.

56. Stoeltzing $O$, Ahmad SA, Liu W, McCarty MF, Parikh AA, Fan F, Reinmuth N, Bucana CD, Ellis LM: Angiopoietin-1 inhibits tumour growth and ascites formation in a murine model of peritoneal carcinomatosis. British Journal of Cancer 2002, 87(10):1182-1187.

57. Stoeltzing O, Ahmad SA, Liu W, McCarty MF, Wey JS, Parikh AA, Fan F, Reinmuth N, Kawaguchi M, Bucana CD, et al: Angiopoietin-1 inhibits vascular permeability, angiogenesis, and growth of hepatic colon cancer tumors. Cancer Research 2003, 63(12):3370-3377.

58. Hawighorst T, Skobe M, Streit M, Hong YK, Velasco P, Brown LF, Riccardi L, Lange-Asschenfeldt B, Detmar M: Activation of the tie2 receptor by angiopoietin-1 enhances tumor vessel maturation and impairs squamous cell carcinoma growth. The American Journal of Pathology 2002, 160(4):1381-1392.

59. Ahmad SA, Liu W, Jung YD, Fan F, Reinmuth N, Bucana CD, Ellis LM: Differential expression of angiopoietin- 1 and angiopoietin-2 in colon carcinoma. A possible mechanism for the initiation of angiogenesis. Cancer 2001, 92(5):1138-1143.

60. Durkin AJ, Bloomston M, Yeatman TJ, Gilbert-Barness E, Cojita D, Rosemurgy AS, Zervos EE: Differential expression of the Tie-2 receptor and its ligands in human pancreatic tumors. Journal of the American College of Surgeons 2004, 199(5):724-731.

61. Ochiumi T, Tanaka S, Oka S, Hiyama T, Ito M, Kitadai Y, Haruma K, Chayama K: Clinical significance of angiopoietin-2 expression at the deepest invasive tumor site of advanced colorectal carcinoma. International Journal of Oncology 2004, 24(3):539-547.

62. Chung YC, Hou YC, Chang CN, Hseu TH: Expression and prognostic significance of angiopoietin in colorectal carcinoma. Journal of Surgical Oncology 2006, 94(7):631-638.

63. Winkler F, Kozin SV, Tong RT, Chae SS, Booth MF, Garkavtsev I, Xu L, Hicklin DJ, Fukumura D, di Tomaso E, et al: Kinetics of vascular normalization by VEGFR2 blockade governs brain tumor response to radiation: role of oxygenation, angiopoietin-1, and matrix metalloproteinases. Cancer Cell 2004, 6(6):553-563.

\section{Pre-publication history}

The pre-publication history for this paper can be accessed here: http://www.biomedcentral.com/1471-2407/11/286/prepub

doi:10.1186/1471-2407-11-286

Cite this article as: Rahbari et al:: Expression and prognostic value of circulating angiogenic cytokines in pancreatic cancer. BMC Cancer 2011 11:286. 